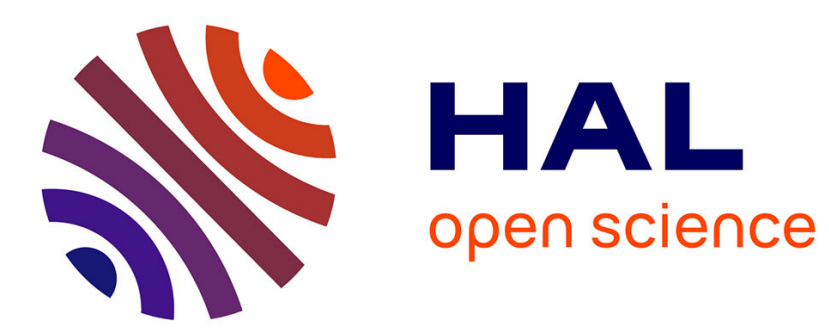

\title{
High-Order Sliding Mode Control for DFIG-Based Wind Turbine Fault Ride-Through
}

Mohamed Benbouzid, Brice Beltran, Yassine Amirat, Yao Gang, Han Jingang, Hervé Mangel

\section{- To cite this version:}

Mohamed Benbouzid, Brice Beltran, Yassine Amirat, Yao Gang, Han Jingang, et al.. High-Order Sliding Mode Control for DFIG-Based Wind Turbine Fault Ride-Through. IEEE IECON 2013, Nov 2013, Vienne, Austria. pp.7670-7674. hal-00926243

HAL Id: hal-00926243

https://hal.science/hal-00926243

Submitted on 9 Jan 2014

HAL is a multi-disciplinary open access archive for the deposit and dissemination of scientific research documents, whether they are published or not. The documents may come from teaching and research institutions in France or abroad, or from public or private research centers.
L'archive ouverte pluridisciplinaire HAL, est destinée au dépôt et à la diffusion de documents scientifiques de niveau recherche, publiés ou non, émanant des établissements d'enseignement et de recherche français ou étrangers, des laboratoires publics ou privés. 


\title{
High-Order Sliding Mode Control for DFIG-Based Wind Turbine Fault Ride-Through
}

\author{
Mohamed Benbouzid, Brice Beltran, Yassine Amirat, Gang Yao, Jingang Han and Hervé Mangel
}

\begin{abstract}
This paper deals with the Fault Ride-Through (FRT) capability assessment of a Doubly-Fed Induction Generator (DFIG)-based Wind Turbine (WT) using High-Order Sliding Mode (HOSM) control. Indeed, it has been recently suggested that sliding mode control is a solution of choice to the FRT problem. In this context, this paper proposes HOSM as an improved solution that handle the classical sliding mode chattering problem. Indeed, the main and attractive features of HOSMs are robustness against external disturbances (e.g. grid) and chattering-free behavior (no extra mechanical stress on the drive train).

Simulations using the NREL FAST code on a 1.5-MW wind turbine are carried-out to evaluate ride-through performance of the proposed HOSM control strategy in case of grid frequency variations and unbalanced voltage sags.
\end{abstract}

Index Terms -Wind turbine (WT), Doubly-Fed Induction Generator (DFIG), Fault-Ride Through (FRT), High-Order Sliding Mode (HOSM).

\section{INTRODUCTION}

An increasing number of power system operators have implemented technical standards known as grid codes that wind turbines must meet when connecting to the grid [1-2]. Generally, these grid codes requirements cover many topics such as, voltage operating range, power factor regulation, frequency operating range, grid support capability, and low fault ride-through capability. Indeed, grid codes dictate Fault Ride-Through (FRT) requirements. Low-Voltage RideThrough (LVRT) capability is considered to be the biggest challenge in wind turbines design and manufacturing technology [3]. LVRT requires wind turbines to remain connected to the grid in presence of grid voltage sags.

The Doubly-Fed Induction Generator (DFIG) is one of the most frequently deployed large grid-connected wind turbines. Indeed, when compared with the full-scale power converter WT concept, the DFIG offers some advantages, such as reduced inverter and output filter costs due to low rotor- and grid-side power conversion ratings $(25 \%-30 \%)$ [4]. However, DFIG-based WTs are very sensitive to grid disturbances, especially to voltage dips [5].

M.E.H. Benbouzid, B. Beltran, and Hervé Mangel are with the University of Brest, EA 4325 LBMS, Rue de Kergoat, CS 93837, 29238 Brest Cedex 03, France (e-mail: Mohamed.Benbouzid@univ-brest.fr, brice.beltran@dga.defense.gouv.fr, Herve.Mangel@univ-brest.fr).

Y. Amirat is with ISEN, EA 4325 LBMS, 20, Rue Cuirassé Bretagne, 29200 Brest, France (e-mail: Yassine.Amirat@isen.fr).

G. Yao and J. Han are with the Shanghai Maritime University, Department of Electrical Automation, 201306 Shanghai, China (email: gangyao@shmtu.edu.cn, jghan@shmtu.edu.cn).
In this context, this paper proposes to address the FRT problems using a so-called active method achieving FRT with no additional devices. The goal is to control rotor voltages and currents, to reduce the rotor overvoltages and/or overcurrents, and therefore avoid the crowbar use/activation in order to keep full DFIG control at all times to meet the FRT requirements. In [6], a critical review of control methods for LVRT compliance with DFIG is given. This state-of-the-art review suggests the need of robust and nonlinear controller. In particular, it has been suggested that sliding mode control is a solution of choice to the FRT problem [7]. Therefore and in this particular context, this paper proposes the use of highorder sliding mode control as an improved solution that handle the classical sliding mode chattering problem. Indeed, the main and attractive features of HOSMs are robustness against external disturbances (e.g. grid) and chattering-free behavior (no extra mechanical stress on the drive train) [8-10].

The proposed control strategy combines an MPPT using a second-order sliding mode for the DFIG control. This strategy presents attractive features such as chattering-free behavior, finite reaching time, robustness and unmodeled dynamics (generator and turbine). To check the overall control strategy ride-through performance, simulations using the NREL FAST code on a 1.5-MW wind turbine are carried-out in case of grid frequency variations and unbalanced voltage sags.

\section{GRID-CODE REQUIREMENTS}

Grid-code requirements typically refer to large wind farms connected to the transmission system, rather than smaller stations connected to the distribution network. These new grid codes stipulate that wind farms should contribute to power system control (frequency and also voltage), much as the conventional power stations, and emphasize wind farm behavior in case of abnormal operating conditions of the network (such as in case of voltage dips). The most common requirements include FRT capability, extended system voltage and frequency variation limits, active power regulation, and frequency control, as well as reactive power/power factor and voltage regulation capabilities [1-2]. Grid codes main requirements regarding the addressed faults are given below.

\section{A. Frequency Operating Range}

Wind power plants are required to run continuously within typical grid frequency variations between $49.5 \mathrm{~Hz}$ and 50.5 $\mathrm{Hz}$. Figure 1 gives an example of frequency-grid voltage variations [1]. 


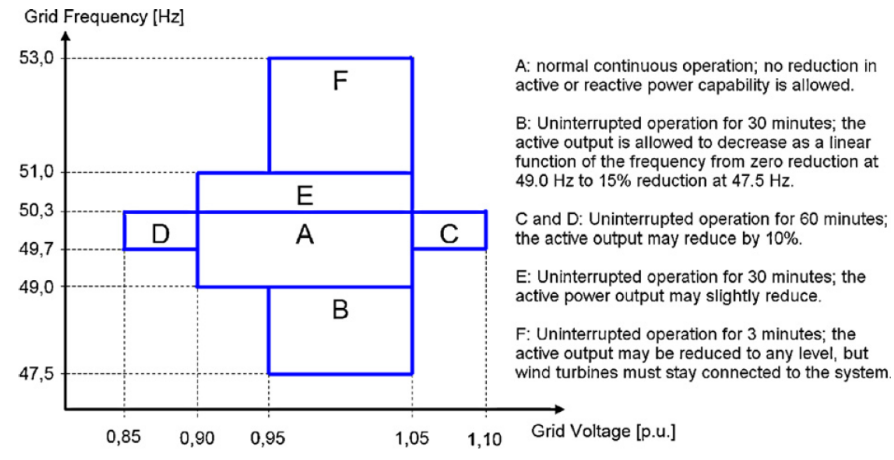

Fig. 1. Frequency-voltage variations ranges [C Nordel] [1].

\section{B. Low Voltage Ride-Through}

Grid codes invariably require that large wind farms must withstand voltage sags down to a certain percentage of the nominal voltage and for a specified duration. Such constraints are known as LVRT requirements. They are described by a voltage versus time characteristic, denoting the minimum required immunity of the wind power station to the system voltage sags (Fig. 2) [1].

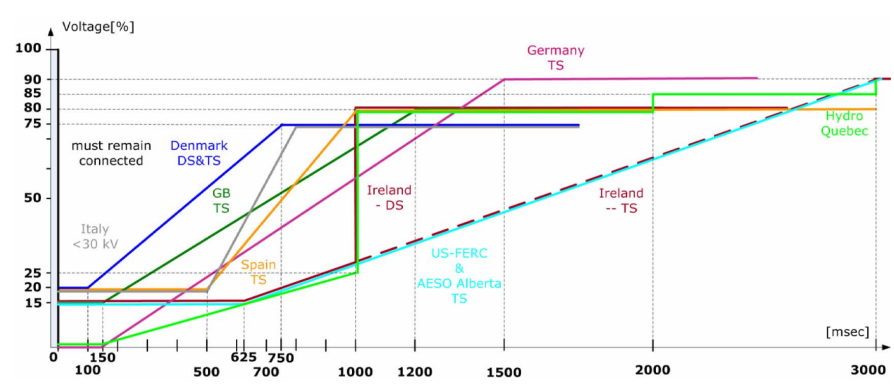

Fig. 2. LVRT requirements for different countries [1].

\section{WIND TURBINE MODELING}

The wind turbine modeling is inspired from [9]. In the following, the wind turbine components models are briefly described.

\section{A. The Turbine Model}

In this case, the aerodynamic power $P_{a}$ captured by the wind turbine is given by

$$
P_{a}=\frac{1}{2} \pi \rho R^{2} C_{p}(\lambda) v^{3}
$$

where the tip speed ratio $\lambda$ is given by $\lambda=\frac{R \omega}{v}$

and $v$ is the wind, $\rho$ is the air density, $R$ is the rotor radius, and $C_{p}$ is the power coefficient.

The rotor power (aerodynamic power) is also defined by
$P_{a}=\omega T_{a}$

where $T_{a}$ is the aerodynamic torque and $\omega$ is the WT rotor speed.

The following simplified model is adopted for the turbine (drive train) for control purposes.

$J \dot{\omega}=T_{a}-K \omega-T_{g}$

where $T_{g}$ is the generator electromagnetic torque, $J$ is the turbine total inertia, and $K$ is the turbine total external damping.

\section{B. The DFIG Model}

The control system is usually defined in the synchronous $d-q$ frame fixed to either the stator voltage or the stator flux. For the proposed control strategy, the generator dynamic model written in a synchronously rotating frame $d-q$ is given by

$\left\{\begin{array}{l}V_{s d}=R_{s} I_{s d}+\frac{d \phi_{s d}}{d t}-\omega_{s} \phi_{s q} \\ V_{s q}=R_{s} I_{s q}+\frac{d \phi_{s q}}{d t}+\omega_{s} \phi_{s d} \\ V_{r d}=R_{r} I_{r d}+\frac{d \phi_{r d}}{d t}-\omega_{r} \phi_{r q} \\ V_{r q}=R_{r} I_{r q}+\frac{d \phi_{r q}}{d t}+\omega_{r} \phi_{r d} \\ \phi_{s d}=L_{s} I_{s d}+M I_{r d} \\ \phi_{s q}=L_{s} I_{s q}+M I_{r q} \\ \phi_{r d}=L_{r} I_{r d}+M I_{s d} \\ \phi_{r q}=L_{r} I_{r q}+M I_{s q} \\ T_{e m}=p M\left(I_{r d} I_{s q}-I_{r q} I_{s d}\right)\end{array}\right.$

where $V$ is the voltage, $I$ the current, $\phi$ is the flux, $R$ is the resistance, $L$ is inductance, $M$ is the mutual inductance, $T_{e m}$ is the electromagnetic torque, and $p$ is the pole pair number.

For simplification purposes, the $q$-axis is aligned with the stator voltage and the stator resistance is neglected. These will lead to

$$
\left\{\begin{array}{l}
\frac{d I_{r d}}{d t}=\frac{1}{\sigma L_{r}}\left(V_{r d}-R_{r} I_{r d}+s \omega_{s} \sigma L_{r} I_{r q}-\frac{M}{L_{s}} \frac{d \phi_{s d}}{d t}\right) \\
\frac{d I_{r q}}{d t}=\frac{1}{\sigma L_{r}}\left(V_{r q}-R_{r} I_{r q}-s \omega_{s} \sigma L_{r} I_{r d}-s \omega_{s} \frac{M}{L_{s}} \phi_{s d}\right) \\
T_{e m}=-p \frac{M}{L_{s}} \phi_{s d} I_{r q}
\end{array}\right.
$$

where $\sigma$ is the leakage coefficient $\left(\sigma=1-M^{2} / L_{s} L_{r}\right), \omega_{r}$ is the angular speed, $\omega_{s}$ is the synchronous speed, and $s$ is the slip. 


\section{DFIG-BASED WIND TURBINE CONTROL}

\section{A. MPPT Strategy}

The control objective is to optimize the capture wind energy by tracking the optimal torque $T_{\text {opt }}$.

$$
T_{o p t}=k \omega^{2}, \text { with } k=\frac{1}{2} \pi \rho R^{5} \frac{C_{p \max }}{\lambda_{o p t}^{3}}
$$

Details about the adopted strategy are given in [9].

\section{B. HOSM Control Strategy}

The DFIG-based WT control objective is to optimize the extracted power by tracking the optimal torque $T_{\text {opt }}(7)$. The control is a compromise between conversion efficiency and torque oscillation smoothing.

The reactive power is expressed as follows.

$Q_{s}=V_{s q} I_{s d}-V_{s d} I_{s q}$

Adapting (8) to our hypotheses, it comes then

$Q_{s}=\frac{V_{s} \phi_{s}}{L_{s}}-\frac{V_{s} M}{L_{s}} I_{r d}$

As the stator reactive power reference is zero, then

$\phi_{s}=\frac{V_{s}}{\omega_{s}} \rightarrow I_{r d_{-} r e f}=\frac{V_{s}}{\omega_{s} M}$

Let us consider the following tracking errors.

$\left\{\begin{array}{c}e_{I_{r d}}=I_{r d}-I_{r d_{-} r e f} \\ e_{T_{e m}}=T_{e m}-T_{r e f}\end{array}\right.$

Then we will have

$\left\{\begin{array}{l}\dot{e}_{I_{r d}}=\frac{1}{\sigma L_{r}}\left(V_{r d}-R_{r} I_{r d}+g \omega_{s} L_{r} \sigma I_{r q}-\frac{M}{L_{s}} \frac{d \phi_{s d}}{d t}\right)-\dot{I}_{r d_{-} r e f} \\ \dot{e}_{T_{e m}}=-p \frac{M}{\sigma L_{s} L_{r}} \phi_{s}\left(\begin{array}{l}V_{r q}-R_{r} I_{r q}-g \omega_{s} L_{r} \sigma i_{r d} \\ -g \omega_{s} \frac{M}{L_{s}} \phi_{s d}\end{array}\right)-\dot{T}_{r e f}\end{array}\right.$

If we define the functions $G_{1}$ and $G_{2}$ as follows.

$$
\left\{\begin{array}{l}
G_{1}=\frac{1}{\sigma L_{r}}\left(g \omega_{s} \sigma L_{r} I_{r q}-\frac{M}{L_{s}} \frac{d \phi_{s d}}{d t}\right)-\dot{I}_{r d_{-} r e f} \\
G_{2}=-p \frac{M}{\sigma L_{s} L_{r}} \phi_{s}\left(-g \omega_{s} \sigma L_{r} I_{r d}-g \omega_{s} \frac{M}{L_{s}} \phi_{s d}\right)-\dot{T}_{r e f}
\end{array}\right.
$$

Thus we have

$$
\left\{\begin{array}{l}
\ddot{e}_{I_{r d}}=\frac{1}{\sigma L_{r}} \dot{V}_{r d}+\dot{G}_{1}-\frac{1}{\sigma L_{r}} R_{r} \dot{I}_{r d} \\
\ddot{e}_{\Gamma_{e m}}=-p \frac{M}{\sigma L_{s} L_{r}} \phi_{s} \dot{V}_{r q}+\dot{G}_{2}+p \frac{M}{\sigma L_{s} L_{r}} \phi_{s} R_{r} \dot{I}_{r q}
\end{array}\right.
$$

Now, lets us consider the following high-order sliding mode controller based on the supertwisting algorithm.

$$
\left\{\begin{array}{l}
V_{r q}=y_{1}+B_{1}\left|e_{T_{e m}}\right|^{\frac{1}{2}} \operatorname{Sgn}\left(e_{T_{e m}}\right)+\frac{1}{\sigma L_{r}} R_{r} I_{r d} \\
\dot{y}_{1}=+B_{2} \operatorname{Sgn}\left(e_{T_{e m}}\right) \\
V_{r d}=y_{2}-B_{3}\left|e_{I_{r d}}\right|^{\frac{1}{2}} \operatorname{Sgn}\left(e_{I_{r d}}\right)-p \frac{M}{\sigma L_{s} L_{r}} \phi_{s} R_{r} I_{r q} \\
\dot{y}_{2}=-B_{4} \operatorname{Sgn}\left(e_{I_{r d}}\right)
\end{array}\right.
$$

Where the constants $B_{1}, B_{2}, B_{3}, B_{4}, \Phi_{1}$, and $\Phi_{2}$ satisfy (15).

$$
\left\{\begin{array}{l}
\left|\dot{G}_{1}\right|<\Phi_{1} \\
B_{1}>p \frac{M}{\sigma L_{s} L_{r}} \phi_{s} \Phi_{1}, B_{2}{ }^{2} \geq \frac{4 \Phi_{1}\left(B_{1}+\Phi_{1}\right)}{\sigma^{2} L_{r}{ }^{2}\left(B_{1}-\Phi_{1}\right)} \\
\left|\dot{G}_{2}\right|<\Phi_{2} \\
B_{3}>\frac{\Phi_{2}}{\sigma L_{r}}, B_{4}{ }^{2} \geq \frac{4 \Phi_{2}\left(B_{3}+\Phi_{2}\right)}{\sigma^{2} L_{r}{ }^{2}\left(B_{3}-\Phi_{2}\right)}
\end{array}\right.
$$

Thus, we can assert that there exist finite times $t_{T e m}$ and $t_{I r d}$ leading to (16).

This means that the control objective is achieved.

$\begin{cases}I_{r d_{-} r e f}=I_{r d}, & \forall t>t_{I_{r d}} \\ T_{r e f}=T_{e m}, & \forall t>t_{T_{e m}}\end{cases}$

The above proposed high-order sliding mode (a second) control strategy for a DFIG-based WT is illustrated by Fig. 3.

\section{SimULATIONS USING FAST CODE}

Simulation using FAST with Matlab-Simulink ${ }^{\circledR}$ have been carried out on the NREL WP 1.5-MW wind turbine (Fig. 4) using turbulent FAST wind data shown by Fig. 5 [11]. The wind turbine, the DFIG ratings, and control parameters are given in the Appendix.

An interface has been developed between FAST and Matlab-Simulink ${ }^{\circledR}$ enabling users to implement advanced turbine controls in Simulink convenient block diagram form (Fig. 6). Hence, electrical model (DFIG, grid, control system, etc.) designed in the Simulink environment is simulated while making use of the complete nonlinear aerodynamic wind turbine motion equations available in FAST (Fig. 7). 


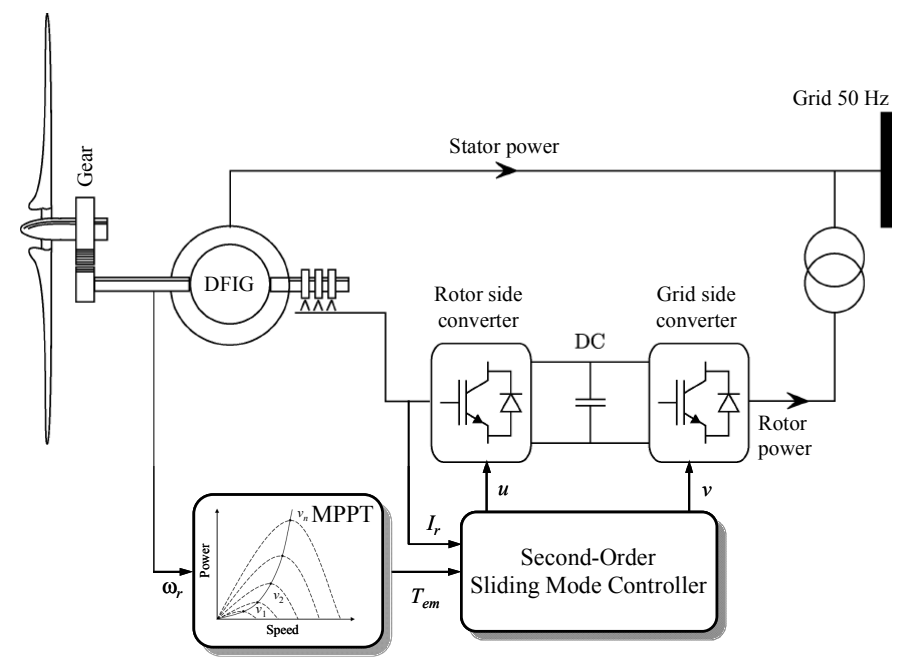

Fig. 3. The proposed FRT control structure.

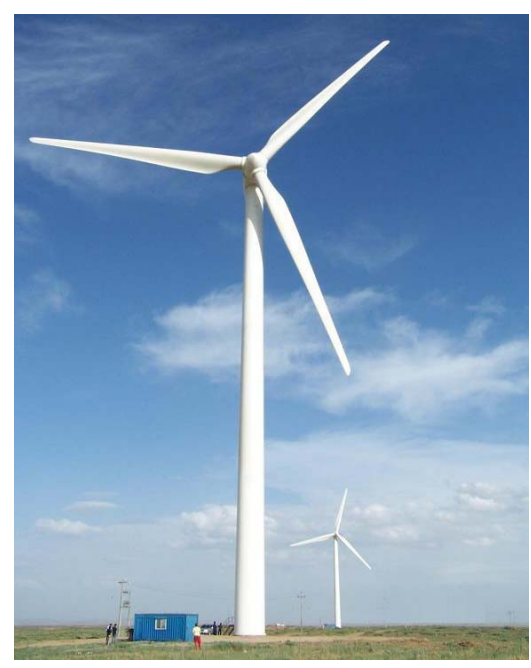

Fig. 4. 1.5-MW wind turbine illustration.

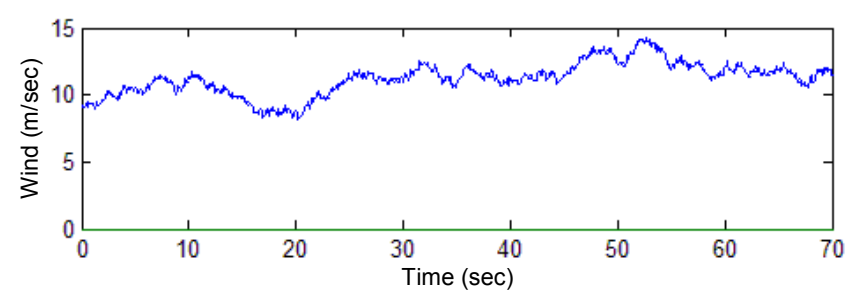

Fig. 5. Wind speed profile.

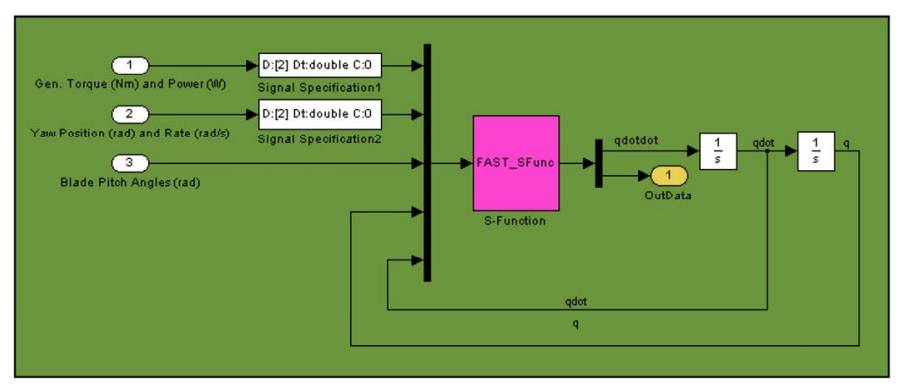

Fig. 6. FAST wind turbine block.

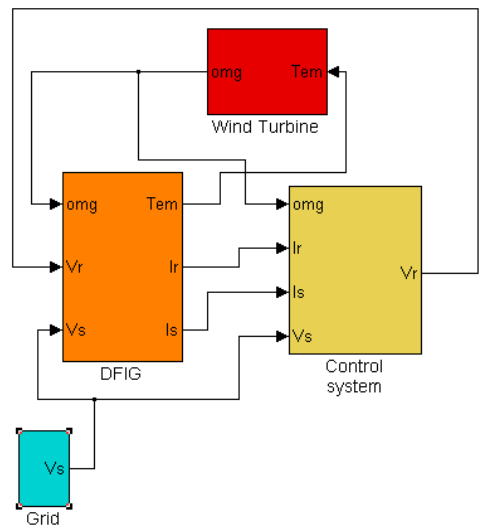

Fig. 7. Simulink model.

\section{A. Frequency Variation}

The proposed HOSM-based FRT strategy will be first tested regarding a frequency variation. Indeed, the studied case is a frequency fall from 50 to $48 \mathrm{~Hz}$ as illustrated by Fig. 8 . This case corresponds to a power generation loss that could lead to a rapid decrease of the grid frequency.

The FRT performances are illustrated by Fig. 9. It clearly shows that the frequency fall has practically no effect on the torque. Indeed, a good tolerance is achieved for this type of fault.

\section{B. Unbalanced Voltage Sags}

When unbalanced sags occur (Fig. 10), very high current, torque, and power oscillations appear at double of the electrical frequency, forcing a disconnection.

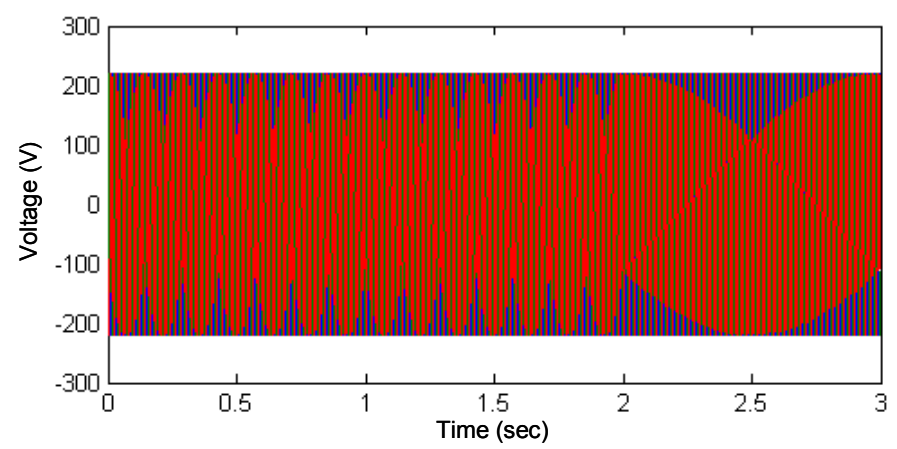

Fig. 8. Grid voltage.

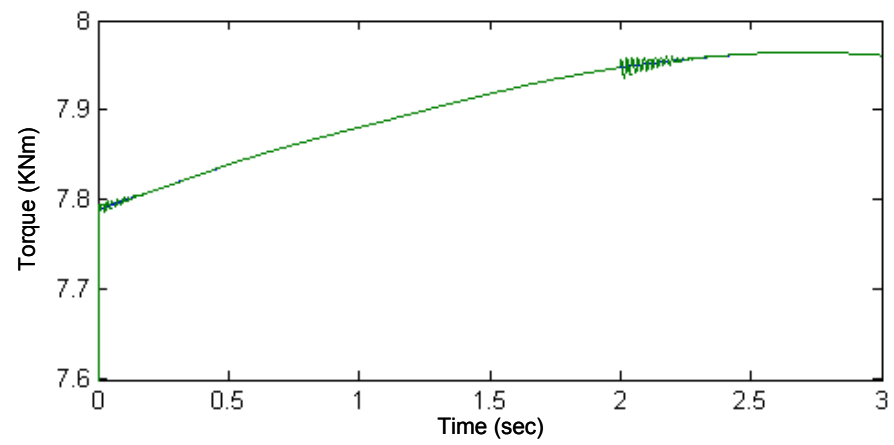

Fig. 9. Torque: Reference (green) and real (blue). 


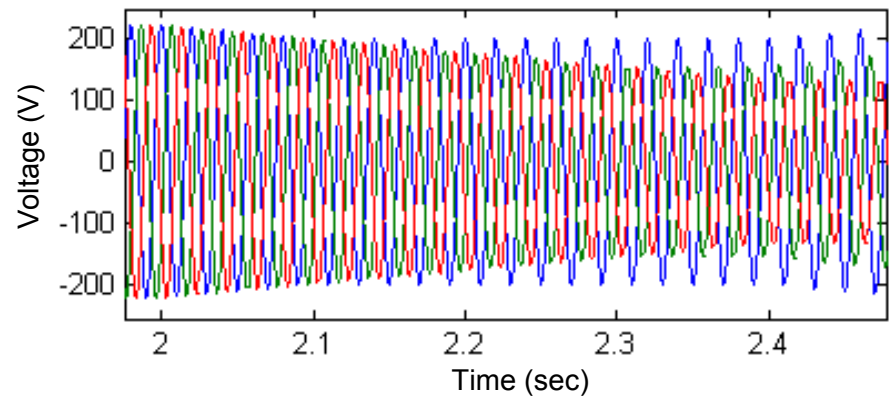

Fig. 10. Grid voltage.

The FRT performances are illustrated by Fig. 11 where an almost constant torque is achieved. Moreover, good tracking performances are also achieved in terms of DFIG rotor current (Fig. 12).

\section{CONCLUSION}

This paper dealt with a high-order sliding mode control of a doubly-fed induction-based wind turbine for fault ride through. The HOSM-based FRT strategy has been tested regarding grid frequency variations and unbalanced voltage sags on a 1.5-MW three-blade wind turbine using the NREL wind turbine simulator FAST. The achieved results show promising successful ride-through performance.

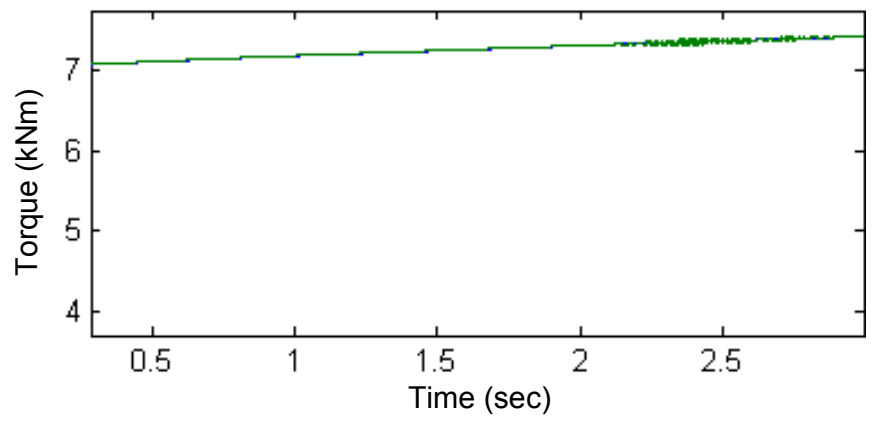

Fig. 11. Torque tracking performance during unbalanced voltage sags: Reference (blue) and real (green).

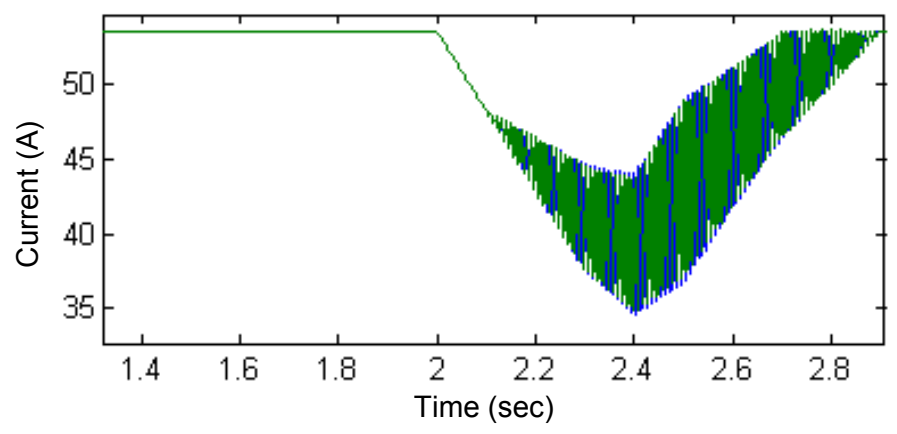

Fig. 12. Current $I_{r d}$ tracking performance during unbalanced voltage sags: Reference (blue) and real (green).
APPENDIX

CHARACTERISTICS OF THE SIMULATED WIND TURBINE

\begin{tabular}{c|c}
\hline \hline Number of blades & 3 \\
\hline Rotor diameter & $70 \mathrm{~m}$ \\
\hline Hub height & $84.3 \mathrm{~m}$ \\
\hline Rated power & $1.5 \mathrm{MW}$ \\
\hline Turbine total inertia & $4.4532 \times 10^{5} \mathrm{~kg} \mathrm{~m}^{2}$ \\
\hline \hline
\end{tabular}

PARAMETERS OF THE SIMULATED DFIG

$R_{s}=0.005 \Omega, L_{s}=0.407 \mathrm{mH}, R_{r}=0.0089 \Omega, L_{r}=0.299 \mathrm{mH}$ $M=0.0016 \mathrm{mH}, p=2$

CONTROL PARAMETERS

$\theta=30, A_{1}=5 \times 10^{3}, A_{2}=1 \times 10^{5}, B_{1}=1.5, B_{2}=50, B_{3}=200, B_{3}=1000$ $k_{\text {opt }}=1.6124 \times 10^{5}$

\section{REFERENCES}

[1] M. Mohseni and S.M. Islam, "Review of international grid codes for wind power integration: Diversity, technology and a case for global standard," Renewable and Sustainable Energy Reviews, vol.16, n6, pp. 3876-3890, August 2012.

[2] M. Tsili and S. Papathanassiou, "A review of grid code technical requirements for wind farms," IET Renewable Power Generation, vol. 3, n³, pp. 308-332, September 2009.

[3] X. Yingcheng and T. Nengling, "Review of contribution to frequency control through variable speed wind turbine," Renewable Energy, vol. 36, n6, pp 1671-1677, June 2011.

[4] M. Liserre, R. Cardenas, M. Molinas and J. Rodriguez, "Overview of multi-MW wind turbines and wind parks," IEEE Trans. Industrial Electronics, vol. 58, n4, pp. 1081-1095, April 2011.

[5] H.T. Jadhav and R. Roy, "A comprehensive review on the grid integration of doubly fed induction generator," International Journal of Electrical Power \& Energy Systems, vol. 49, pp. 8-18, July 2013.

[6] R. Cardenas, R. Pena, S. Alepuz and G. Asher, "Overview of control systems for the operation of DFIGs in wind energy applications," IEEE Trans. Industrial Electronics, vol. 60, n7, pp. 2776-2798, July 2013.

[7] M.I. Martinez, G. Tapia, A. Susperregui and H. Camblong, "Slidingmode control for DFIG rotor- and grid-side converters under unbalanced and harmonically distorted grid voltage," IEEE Trans. Energy Conversion, vol. 27, n², pp. 328-339, June 2012.

[8] B. Beltran, M.E.H. Benbouzid and T. Ahmed-Ali, "Second-order sliding mode control of a doubly fed induction generator driven wind turbine," IEEE Trans. Energy Conversion, vol. 27, n², pp. 261-269, June 2012.

[9] B. Beltran, T. Ahmed-Ali and M.E.H. Benbouzid, "High-order sliding mode control of variable speed wind turbines," IEEE Trans. Industrial Electronics, vol. 56, n9, pp. 3314-3321, September 2009.

[10] M.E.H. Benbouzid, B. Beltran, H. Mangel and A. Mamoune, "A highorder sliding mode observer for sensorless control of DFIG-based wind turbines," in Proceedings of the 2012 IEEE IECON, Montreal (Canada), pp. 4288-4292, October 2012.

[11] http://wind.nrel.gov/designcodes/simulators/fast/. 